\title{
Article \\ Static and Impact Response of a Single-Span Stone Masonry Arch
}

\author{
Bora Pulatsu $^{1, *(1)}$, Semih Gonen ${ }^{2}(\mathbb{C})$ and Paulo B. Lourenço ${ }^{3}$ \\ 1 Department of Civil and Environmental Engineering, Carleton University, Ottawa, ON K1S 5B6, Canada \\ 2 Department of Civil Engineering and Energy Technology, Oslo Metropolitan University, \\ NO-0130 Oslo, Norway; semihgon@oslomet.no \\ 3 ISISE, Department of Civil Engineering, Campus de Azurém, University of Minho, \\ 4800-058 Guimaraes, Portugal; pbl@civil.uminho.pt \\ * Correspondence: bora.pulatsu@carleton.ca
}

Citation: Pulatsu, B.; Gonen, S.; Lourenço, P.B. Static and Impact Response of a Single-Span Stone Masonry Arch. Infrastructures 2021, 6, 178. https://doi.org/10.3390/ infrastructures6120178

Academic Editor: Chris Goodier

Received: 22 November 2021 Accepted: 13 December 2021 Published: 16 December 2021

Publisher's Note: MDPI stays neutral with regard to jurisdictional claims in published maps and institutional affiliations.

Copyright: (c) 2021 by the authors. Licensee MDPI, Basel, Switzerland. This article is an open access article distributed under the terms and conditions of the Creative Commons Attribution (CC BY) license (https:// creativecommons.org/licenses/by/ $4.0 /)$.

\begin{abstract}
Unreinforced masonry structures are susceptible to man-made hazards such as impact and blast loading. However, the literature on this subject mainly focuses on masonry wall behavior, and there is a knowledge gap about the behavior of masonry arches under high-strain loading. In this context, this research aims to investigate both quasistatic and impact response of a dry-joint stone masonry arch using the discrete element method. Rigid blocks with noncohesive joint models are adopted to simulate dry-joint assemblages. First, the employed modeling strategy is validated utilizing the available experimental findings, and then sensitivity analyses are performed for both static and impact loading, considering the effect of joint friction angle, contact stiffness, and damping parameters. The outcomes of this research strengthen the existing knowledge in the literature regarding the computational modeling of masonry structures that are subjected to usual and extreme loading conditions. The results highlight that applied discontinuum-based numerical models are more sensitive to stiffness parameters in high-strain loading than static analysis.
\end{abstract}

Keywords: impact; DEM; masonry arches; collapse mechanism; computational modeling

\section{Introduction}

Masonry represents the most widespread construction technique worldwide with different load-bearing structural forms (arches, domes, piers, etc.) and is known as the oldest construction technique, which mankind has been using since the earliest times. Despite their widespread use, masonry structures are vulnerable to hazards. In addition to threats from natural hazards, infrastructures have suffered a lot from extreme loadings resulting from man-made hazards. These include impacts from fast-moving projectiles, blasts, and shocks resulting from explosions.

Early studies on the impact and blast response of masonry focused on testing of unreinforced (URM) [1] and reinforced masonry walls [2], investigating the vehicle-induced impact loading. A recent experimental work [3] demonstrated the differences in the structural properties of a masonry infill wall after an internal blast in a full-scale building. Pourfalah et al. studied the out-of-plane behavior of masonry walls reinforced with cementitious composites subjected to blast loading [4]. However, experimental studies on the impact and blast-induced response of masonry structures are still limited, given the fact that they are costly and challenging to perform in the laboratory environment. As a result, most of the literature on this topic comprises numerical simulations. Amongst various approaches, the researchers mostly applied finite element analysis (FEA) with different levels of complexity and utilized various tools. Refs. [5,6] evaluated the collapse mechanism and performance of masonry structures subjected to high strain loading by considering the masonry as a homogenous medium, referred to as macromodeling. Alternative to macromodeling, joint interfaces can be considered explicitly in both static and high-strain 
loading to address the joint opening, sliding, and unit detachment that may occur during the analysis, referred to as simplified micromodeling [7-10]. Recently, Rafsanjani et al. [7] proposed a dynamic interface model and implemented into a commercial finite element code to capture high strain rate effects on the unreinforced masonry walls subjected to lowvelocity impacts. Burnett et al. [8] used deformable solid elements in FEA and specifically formulated contact models for masonry joints to capture nonlinear effects. These FEAbased simulations were performed using different commercial FE software packages (e.g., ABAQUS, ANSYS, etc.), but researchers also developed different modeling strategies using noncommercial codes. For instance, a rigid-plastic homogenized model [11] and a rigid block and spring homogenized model [12] were proposed as non-commercial solutions for impact-load analysis on masonry structures. Furthermore, a mixed discrete-finite element model was used by Forgacs et al. [13] to investigate dynamic response of a masonry bridge. In addition to the knowledge acquired in previous numerical research, recent analyses focused on the damage and failure of URM walls with and without openings due to low- [14] and high-velocity [15] vehicular impact.

Despite the work carried out on the impact and blast response of masonry walls with a flat geometry, the behavior of curvilinear geometries under these types of loadings has not been widely studied, as indicated by Masi et al. [16]. Their study is a rare example of research investigating the blast behavior of curved masonry structures, particularly vaults, using the discrete element method (DEM).

As evident from the briefly presented literature, there is still a need to determine the behavior of curved masonry elements under impact and blast loading. In this context, the masonry arch is the most commonly used structural element; especially, masonry arches constitute the vast majority of historic buildings, bridges, and monumental structures. Arches also form the basis of more complex elements such as vaults and domes. Their response to impact and blast loading is crucial to prevent catastrophic local and global damage and total collapse of structures.

Hence, this study aims to investigate both quasistatic and impact response of a single span stone masonry arch using DEM, which falls into the category of simplified micromodeling. The explicit solution-procedure of DEM provides computationally efficient solutions for highly discontinuous systems and better captures the dynamic response of blocky structures subjected to impact loading. First, the applied modeling strategy is validated using recent experimental findings. The benchmark study consists of quasistatic and impact testing of dry-joint masonry arches. Six dry-joint stone masonry arches were used with different test setups corresponding to nonidentical impact energies to investigating the impact behavior. Then, the effect bond properties were explored through the proposed computational models in light of the results given in the reference study.

\section{Background: Discrete Element Modeling}

The computational modeling of masonry structures can be categorized under two groups: continuum and discontinuum-based solutions. Typically, the former approach represents the composite nature of masonry as a fictitious homogenous isotropic/orthotropic continuum without making any distinction between the masonry constituents, referred to as macromodeling [17-19]. The material properties employed in macromodels correspond to averaged constitutive relationships obtained from experiments or homogenization techniques [20]. Moreover, the damage is smeared out through continuous medium unless any special crack-localization algorithm is employed (e.g., proposed in [21,22]). Conversely, the discontinuum-based approach, called micromodeling, explicitly considers the mortar, unit, and unit-mortar interface in the numerical formulation, allowing to simulate crack localization and address the distinctive morphological features of masonry structures $[10,23,24]$. However, micromodels require a large number of input parameters and demand a high computational cost to analyze even a small section of complex load-bearing masonry systems (e.g., wall, arch, vault, etc.). Therefore, simplified micromodeling is preferable to compromise the computational cost and accuracy, where the masonry units are expanded 
up to the half-thickness of the mortar joints, whereas the effect of mortar joints is taken into account via zero-thickness interfaces. In the case of dry-joint masonry constructions, masonry units are directly represented by discrete blocks $[25,26]$, as illustrated in Figure 1.

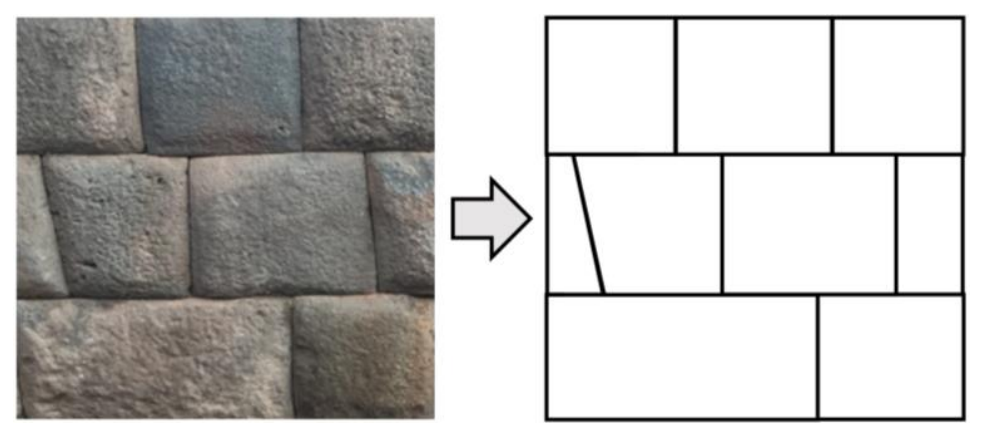

Figure 1. Illustration of dry-joint wall construction and its DEM representation.

In this study, a simplified micromodeling approach is utilized to analyze both static and impact responses of dry-joint stone masonry arches using the discrete element method (DEM). In the early 1970s, DEM was developed by Cundall [27] to analyze the progressive collapse mechanism of the jointed rock masses. Since then, it has been adopted by various disciplines and utilized to simulate a wide range of engineering problems (from micro- to macroscale). In DEM, the discontinuous nature of the material is explicitly demonstrated by distinct rigid and/or deformable blocks that can mechanically interact along their boundaries. This research uses rigid blocks with six degrees of freedom (three translational and three rotational) to analyze the stone masonry arch, considering that the failure is governed by the joint opening and sliding phenomena.

Briefly, the computational procedure of DEM relies on the integration of the equations of motion (both translational and rotational), including gravitational, external, and contact forces to compute the translational and angular velocities at each time step [28,29]. The governing differential equations of translational and angular motion for a discrete block are given in Equations (1) and (2), respectively.

$$
\begin{gathered}
\ddot{u}_{i}+\alpha \dot{u}_{i}=\frac{\Sigma F_{i}}{m}+g_{i} \\
\omega_{i}+\alpha \dot{\omega}_{i}=\frac{\Sigma M_{i}}{I}
\end{gathered}
$$

where $\dot{u}$ is the velocity (prescribed for the centroid of the block); $m$ is the block mass; $g$ is the acceleration vector; $\Sigma F$ denotes the sum of the forces (including external and contact forces); $\omega$ corresponds to the angular velocity; $\Sigma M$ is the sum of moments (including moments produced by contact and applied forces); $I$ is the moment of inertia (computed approximately based on the average distance from the centroid of the vertices of the blocks), and finally, $\alpha$ is the damping parameter. The differential equations are solved via the central difference method in an explicit scheme for each block in the system. Note that new velocities are obtained by evaluating the translational and angular velocities at the midintervals of the time step $\left(\Delta t ; t^{+}=t+\Delta t / 2, t^{-}=t+\Delta t / 2\right)$ as follows:

$$
\begin{gathered}
\dot{u}_{i}^{t+}=\left[\left(1-\frac{c \Delta t}{2}\right) \dot{u}_{i}^{t-}+\left(\frac{\Sigma F_{i}^{t}}{m}+g_{i}\right) \Delta t\right] \frac{1}{1+\frac{c \Delta t}{2}} \\
\omega_{i}^{t+}=\left[\left(1-\frac{c \Delta t}{2}\right) \omega_{i}^{t-}+\frac{\Sigma M_{i}^{t}}{I} \Delta t\right] \frac{1}{1+\frac{c \Delta t}{2}}
\end{gathered}
$$

Once the new velocities are obtained, displacement and rotation increments are calculated $\left(\Delta u_{i}=\dot{u}_{i}^{t+} \Delta t, \Delta \theta_{i}=\omega_{i}^{t+} \Delta t\right)$, and block positions are updated accordingly. 
The new configuration of the discrete block system is further utilized to compute relative displacements among the adjacent blocks, where orthogonal springs are defined at the contact points. In Figure 2, a typical example of a point contact is illustrated in a 2D setting for simplicity in the drawing. The recognized point contacts (PC) follow the softcontact approach, meaning that the interpenetration between the blocks is allowed and controlled by the defined contact stiffness in the normal and shear directions (see Figure 2). Since deformations are lumped at the joints, both linear and nonlinear response of the discontinuous system is governed by the elasto-plastic contact constitutive laws defined at the contact points. In other words, the elastic behavior is controlled by the contact springs prescribed in the normal $\left(k_{n}\right)$ and shear directions $\left(k_{s}\right)$. Furthermore, the Coulomb slip joint model (i.e., $\tau=c+\sigma \tan \phi$; $c$ : cohesion, $\phi$ : friction angle and $\sigma$ : vertical stress) with tension cut-off is used as the nonlinear constitutive model for shear. Tensile forces are limited by the assigned tensile strength $\left(f_{T}\right)$ while no compression failure is considered since it does not influence the collapse mechanism. It should be noted that the cohesion and tensile strength are taken as zero, given the fact that the focus of this research is dry-joint masonry arch analysis.
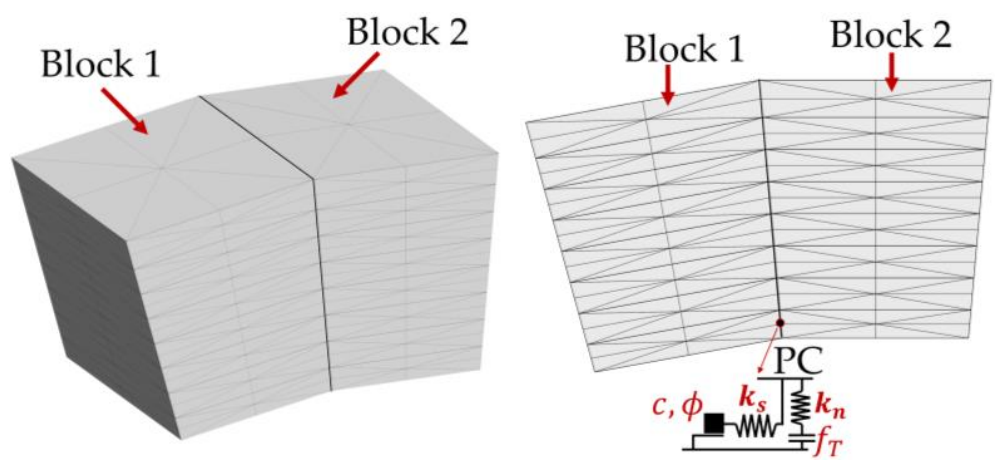

Figure 2. Representation of point contact (PC) in $2 \mathrm{D}$ defined between two blocks $\left(c\right.$ and $f_{T}$ are taken as zero to obtain dry-joint contact behavior).

The new contact stresses are multiplied with the associated contact area and then utilized as contact forces in the equations of motion (Equations (3) and (4)). The explained calculations are executed in an explicit dynamic scheme both for static and dynamic analysis. It is also worth mentioning that quasistatic solutions are obtained by adopting Cundall's local damping formulation [9,30], whereas Rayleigh damping (consisting of mass and stiffness proportions) is used for the dynamic analysis [31,32]. Moreover, the common-plane approach is utilized to trace and recognize new contact points during the analysis, which is essential for impact simulations [33]. Throughout this study, a commercial three-dimensional discrete element code, 3DEC, developed by ITASCA, is used to perform quasistatic and dynamic analysis [34].

\section{Benchmark Experiment: Static and Impact Loading on the Single-Span Stone Masonry Arch}

In this section, experimental findings associated with the benchmark study [35] are presented. An experimental setup was designed to assess the quasistatic and dynamic response of a free-standing stone masonry arch in the civil engineering department laboratory at the University of Minho (Portugal). The masonry arch was assembled utilizing a steel frame composed of I-section steel girders, providing a much more robust and stiffer support system to the arch specimen, as illustrated in Figure 3. The arch consisted of 12 voussoirs, a keystone, and abutment stones, all made of granite stone blocks. The stone units were prefabricated by a company, Artecanter, and prepared using a rotary sawing machine to cut the stones. It should be noted that stone surfaces were not perfectly smooth. The rise, clear span, and thickness of the arch are, $H_{A}=400 \mathrm{~mm}, L_{A}=1200 \mathrm{~mm}$, and $t_{A}=200 \mathrm{~mm}$, respectively. 


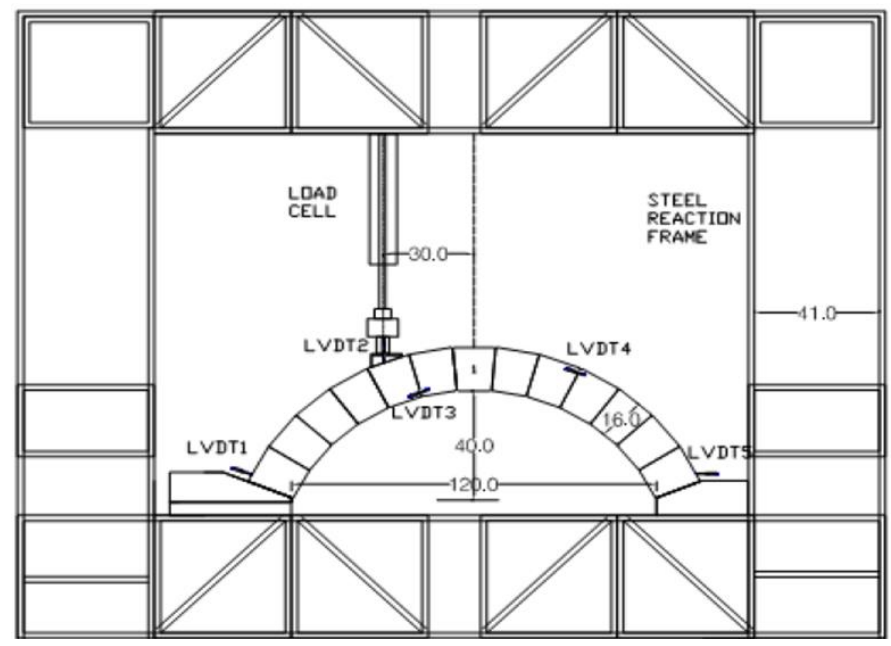

Figure 3. Quasistatic testing of a stone masonry arch (dimensions are in $\mathrm{cm}$ ) [35].

The physical and mechanical characterization of the granite stone blocks and the joint interfaces were performed via extensive laboratory tests. The unit weight of granite stones was obtained as $\gamma=24 \mathrm{kN} / \mathrm{m}^{3}$ [36]. The uniaxial compressive strength of stone units, $f_{c, u}$, tensile strength, $f_{t, u}$, the Young's modulus under compression and tension, $E_{\mathcal{c}}$ and $E_{t}$, and the tensile fracture energy, $G_{f}^{I}$, were obtained. The results pertinent to this study are presented in Table 1, and the reader is referred to another study [36] for the details.

Table 1. Uniaxial mechanical properties of granite stone units.

\begin{tabular}{cccc}
\hline & & Fresh Granite & Weathered Granite \\
\hline Compressive Strength & $f_{c, u}\left(\mathrm{~N} / \mathrm{mm}^{2}\right)$ & 148 & 90 \\
Elasticity Modulus & $E_{c}\left(\mathrm{~N} / \mathrm{mm}^{2}\right)$ & 52,250 & 35,090 \\
Tensile Strength & $f_{t, u}\left(\mathrm{~N} / \mathrm{mm}^{2}\right)$ & 6.01 & 3.52 \\
Elasticity Modulus & $E_{t}\left(\mathrm{~N} / \mathrm{mm}^{2}\right)$ & 12,550 & 3180 \\
Fracture Energy & $G_{f}^{I}\left(\mathrm{~N} / \mathrm{mm}^{2}\right.$ & 0.148 & 0.200 \\
\hline
\end{tabular}

\subsection{Quasistatic Loading}

First, a quasistatic loading of the dry-joint masonry arch was performed. A wooden bearing was glued to the fifth voussoir at the quarter span, where the load was applied and gradually increased until the failure during the quasistatic tests. A steel bearing and a roller on top were placed between the actuator so that no rotational restraint exists among the arch and the actuator. Five linear variable displacement transducers (LVDTs) were used to measure the displacements. Two LVDTs aimed to measure the sliding at the arch-abutment interfaces, one LVDT measured the displacement at the loading point, and the other two LVDTs were placed at the right and left quarter spans to measure the openings between the stones at the expected hinge locations.

The displacement-controlled loading with $0.005 \mathrm{~mm} / \mathrm{s}$ loading rate, was applied and the peak load was recorded as $2.71 \mathrm{kN}$. Maximum vertical displacement reached $12 \mathrm{~mm}$ as the peak strength decreased by $35 \%$, and the loading was removed before the collapse. The deformed shape of the arch at the ultimate displacement is presented in Figure 4. Three rotational and one sliding hinges were observed during the testing, as depicted in Figure 4. 


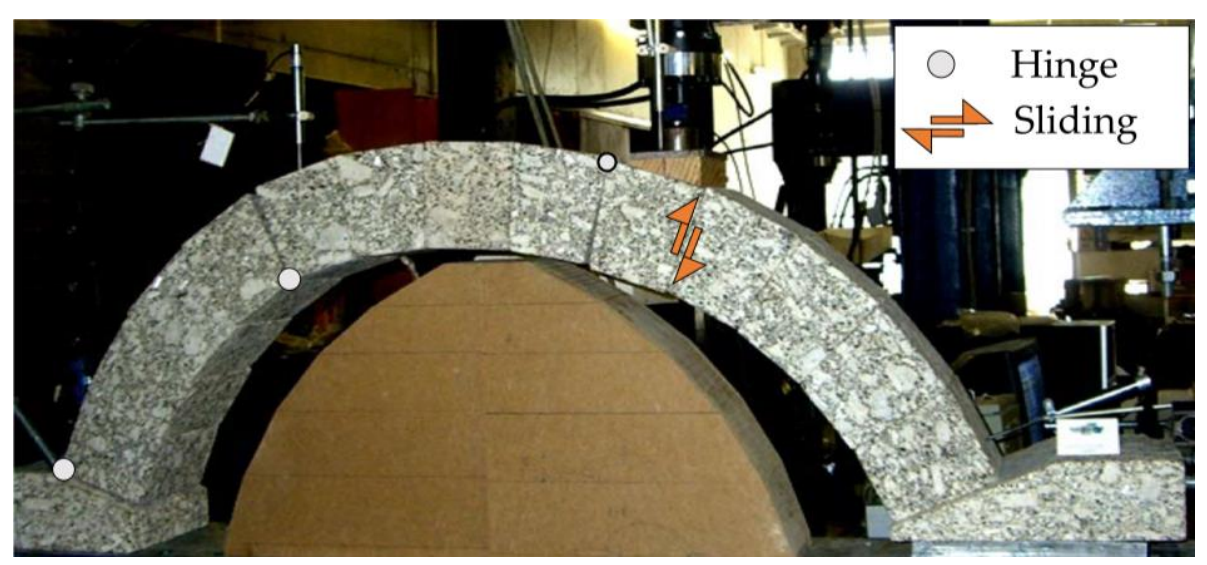

Figure 4. Deformed shape of the arch at the ultimate displacement, retrieved from [35].

\subsection{Impact Loading}

To characterize the performance of stone masonry arches at high-rate loading, singlespan stone masonry arches were subjected to impact loading. The arches were constructed using the same stone units and then tested using a drop-weight apparatus. The abutments were laterally restrained using steel ties to prevent any premature support failure during the testing. Six different test setups were configured for various combinations of drop weight and height. The test setups were labeled to refer to the drop weight and drop height, as presented in Table 2. For instance, M60H30 indicates a test specimen subjected to an impact from a mass of $60.93 \mathrm{~kg}$ dropping from a height of $30.5 \mathrm{~cm}$. The testing details, together with the observational data are given in Table 2. Note that the different results obtained for similar target kinetic energies represents the inherent variability of the masonry properties and real-life experiments.

Table 2. Impact test setups and observed global response after test execution.

\begin{tabular}{cccccc}
\hline & Test Setup & Drop Weight (kg) & Drop Height (cm) & $\begin{array}{c}\text { Target Kinetic } \\
\text { Energy (J) }\end{array}$ & $\begin{array}{c}\text { Response after } \\
\text { Impact }\end{array}$ \\
\hline & M80H45 & 81.00 & 45.0 & 357.6 & Full collapse \\
M75H45 & 74.35 & 45.5 & 331.9 & Full collapse \\
Dry-joint Masonry & 74.35 & 20.5 & 149.5 & Full collapse \\
& M75H20 & 60.93 & 20.5 & 122.5 & Hinge (3R+1S) \\
& M60H20 & 60.93 & 25.5 & 152.5 & Hinge (3R+1S) \\
& M60H25 & 60.93 & 30.5 & 182.3 & Hinge (3R+1S) \\
\hline
\end{tabular}

The failure mechanisms observed for the dry-joint masonry arch were the total collapse of the arch and the formation of three rotational and one sliding hinge. Two rotational hinges centered at the extrados and intrados of the left and right quarter span, one rotational hinge at the right arch-abutment interface, and one sliding hinge at the left quarter span below the loading point were formed. Two of the dry-joint masonry arches at their deformed status after the impact tests are shown in Figure 5.

During each test, an ultra-high-speed camera, recording $3000 \mathrm{fps}$, was positioned at the quarter span to track the position below the impactor point (see Figure 6). Recorded videos were then processed to determine the displacement, velocity, and acceleration of the tracking point. The peak values obtained for each test are presented in Table 3. The maximum displacement (vertical) recorded during the experiment was $0.053 \mathrm{~m}$ for $\mathrm{M} 60 \mathrm{H} 30$, while no recording was obtained for half of the testing $(\mathrm{M} 75 \mathrm{H} 20, \mathrm{M} 75 \mathrm{H} 20$, and $\mathrm{M} 80 \mathrm{H} 45)$ due to the failure of the masonry arch. The progressive joint failure due to impact loading of the dry-joint stone masonry arch is presented in Figure 6. 


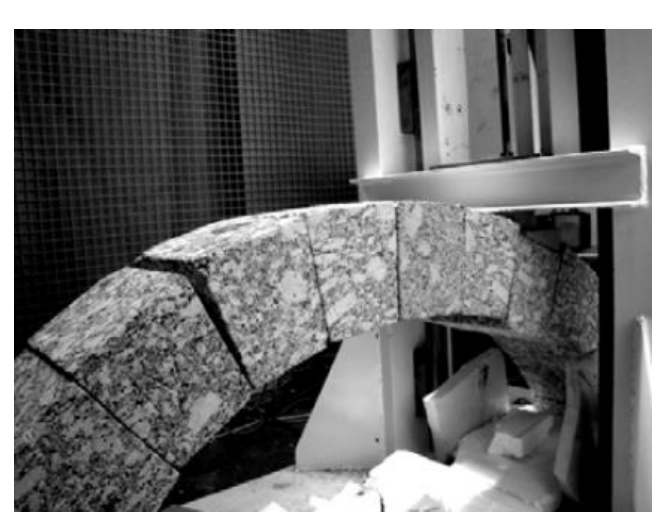

(a) $\mathrm{M} 60 \mathrm{H} 20$

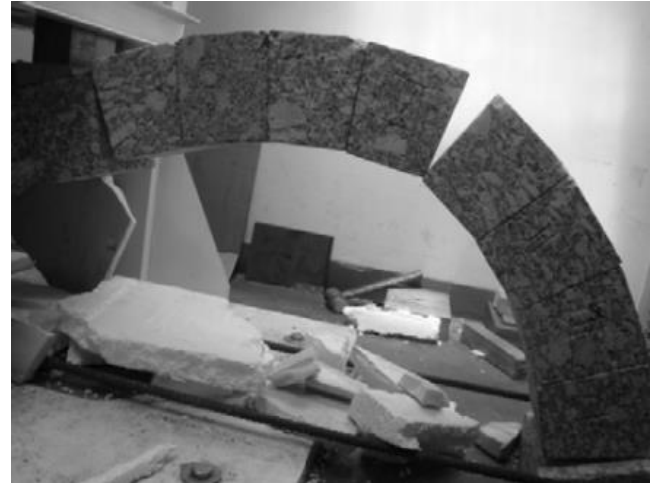

(b) $\mathrm{M} 60 \mathrm{H} 30$

Figure 5. Dry-joint masonry arches after the impact test, retrieved from [35].
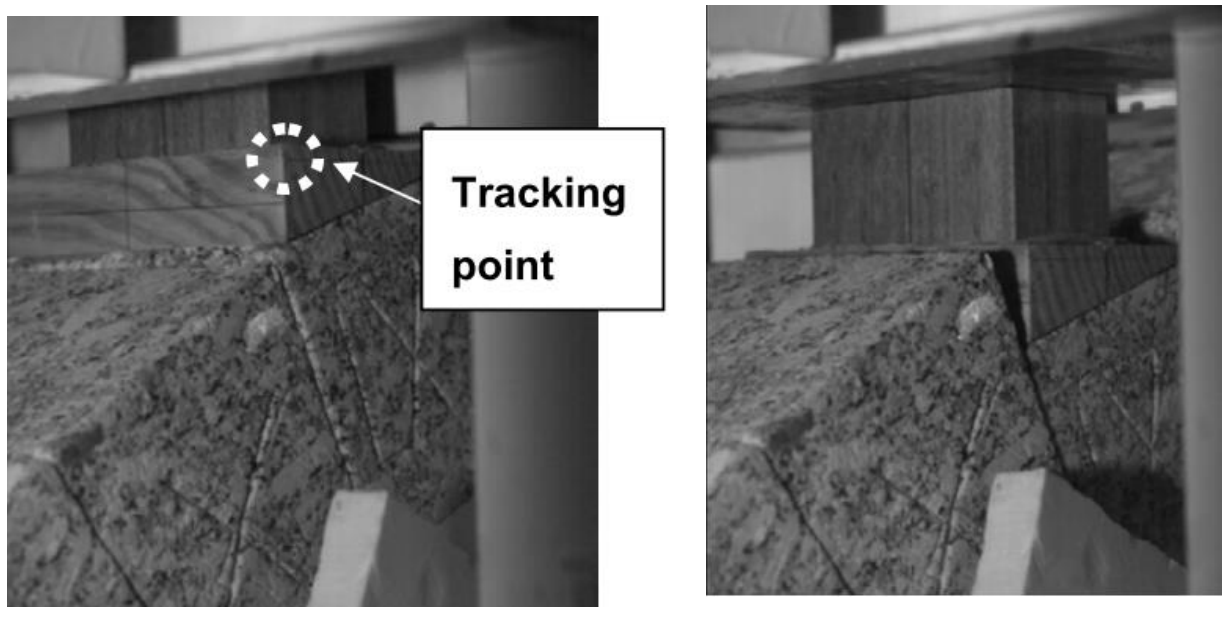

Figure 6. Status of the joint right at the moment of impact (left) and after the impact (right), retrieved from [35].

Table 3. Maximum vertical responses obtained at quarter span during the experiments.

\begin{tabular}{ccccc}
\hline & Test Setup & Displacement $(\mathbf{m})$ & Velocity $(\mathbf{m} / \mathbf{s})$ & Acceleration $\left(\mathbf{m} / \mathbf{s}^{\mathbf{2}}\right)$ \\
\hline & M80H45 & $*$ & 3.19 & 5115.4 \\
M75H45 & $*$ & 2.99 & 2138.6 \\
Dry-joint Masonry & $*$ & 1.91 & 1416.3 \\
& M65H20 & 0.034 & 1.99 & 1417.1 \\
& M60H25 & 0.040 & 2.13 & 1588.6 \\
& M60H30 & 0.053 & 2.08 & 1440.1 \\
\hline
\end{tabular}

* The arch fully collapsed during the test.

\section{DEM-Based Analysis of the Masonry Arch under Static and High-Rate Loadings}

In this section, experimental findings associated with the benchmark study [35] are simulated using the proposed DEM-based models explained earlier. The same geometrical properties are adopted in the numerical model consisting of rigid blocks with noncohesive contact properties. There are 15 contact points defined along each joint edge in the discrete element model to obtain accurate stress distributions, discussed in $[10,37]$. The normal and shear contact stiffnesses are predicted as $4 \mathrm{GPa} / \mathrm{m}$ and $1.6 \mathrm{GPA} / \mathrm{m}$, in line with the previous studies $[38,39]$, which corresponds to the combined stiffness of masonry unit and stone masonry joints (related to the joint roughness and irregularities). Furthermore, joint friction angle is estimated through inverse engineering discussed in the following section in detail. 


\subsection{Modeling Quasistatic Loading Using DEM}

Initially, quasistatic analysis of dry-joint masonry arch is performed imposing a vertical displacement rate to the loading plate (prescribed as fix velocity to the block), shown in Figure 7. The support blocks (abutments) are fixed, and zero cohesion and zero tensile strength are employed, allowing only frictional resistance at the joints. Furthermore, the initial friction angle ( $\phi_{0}=30.5$ degrees $)$ is also used for residual friction angle $\left(\phi_{\text {res }}\right)$ to obtain elasto-plastic shear (sliding) failure based on the experimental findings [40]. The reaction forces (normal to the contact surface) under the loading plate are recorded during the analysis using a FISH function (an executable programming language in 3DEC). The obtained failure mechanism captures closely the experimental results where combined rotational (three hinges) and sliding failures were noted (see Figure 7).

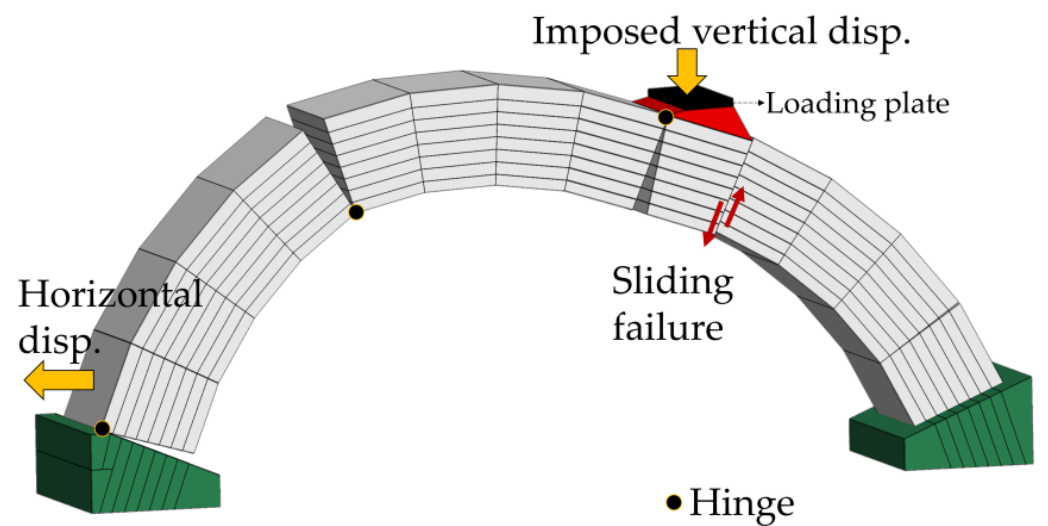

Figure 7. Collapse mechanism (three plastic hinges and sliding failure) obtained by discrete element model.

The deformations are monitored at two points in the computational model, (i) vertical displacement of the loading plate and (ii) horizontal displacement of the stone unit located adjacent to the support (see Figure 7). Discrete element models are used to perform quasistatic analysis under small and large displacement assumptions, in which the latter one takes into account the geometrical nonlinearities while the former does not. The results presented in Figure 8 indicate a good agreement between numerical solutions and the experimental findings, especially when considering geometrical nonlinearities. Although large deformation assumption provides a better fit for the post-peak response of the test results compared to the other one, the difference in terms of maximum load is negligible. This result aligns with the previous findings of different computational models as discussed in [41].

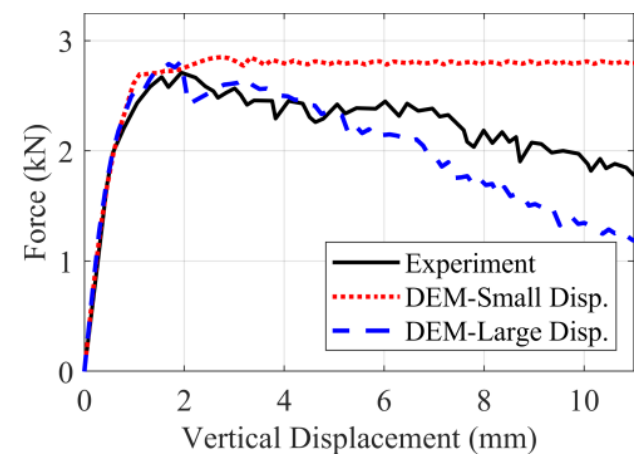

(a)

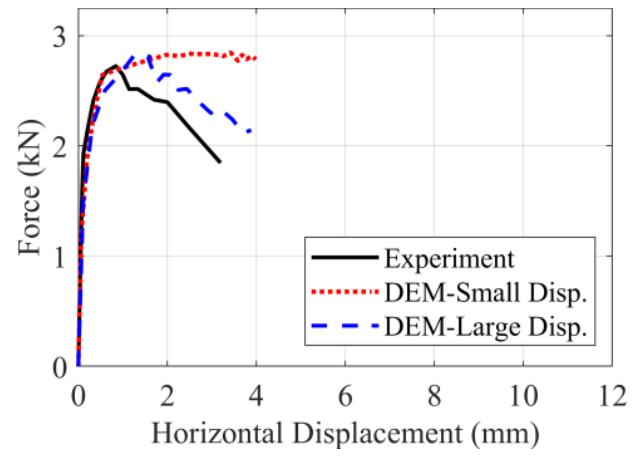

(b)

Figure 8. Comparison of the force-displacement curves between the experiment and DEM-based models (including small and large displacement analysis); (a) vertical displacement, (b) horizontal displacement. 
To better understand the influence of frictional resistance and the contact stiffness, a set of sensitivity analyses are performed using the validated discrete element models, including large displacement formulation. It is observed that the friction angle has no significant effect on the maximum vertical load unless it is below 30 degrees; however, it has a clear effect regarding the post-peak response of the numerical models, as shown in Figure 9a. The premature failure mechanism is obtained using a 27 degrees friction angle, where no hinging mechanism is noted, and the arch failed due to pure sliding failure (Figure 10). On the other hand, failure is governed merely by the plastic hinges when relatively high frictional resistance is defined at the joints ( $\phi_{0}=35$ degrees), given in Figure 10. Since the experimental findings are in-between those cases, friction angle is estimated via inverse-engineering to better match the experimental collapse mechanism, as discussed by the authors in another study [42]. The numerical solution suggests that an excellent match is obtained when $\phi_{0}=30.5$ degrees, in terms of collapse mechanism and force-displacement behavior. The relation between the maximum vertical force and the joint friction angle is shown in Figure 9b. The results clearly reveal that approximately 30 degrees of friction angle can be considered as a limit to shift the structural behavior from plastic hinging mechanism to sliding-induced failure mechanism. Additionally, lower and higher contact stiffnesses are defined at the joints compared to the reference value $\left(k_{n}=4 \mathrm{GPa} / \mathrm{m}\right)$ while keeping the friction angle as $\phi_{0}=30.5$ degrees. Although results do not indicate any substantial difference in the failure mode and capacity, the deformation limit obtained for the maximum load is considerably varied, and post-peak response is remarkably influenced by the contact stiffness, shown in Figure 9c. This suggests that input contact stiffness should be carefully determined, given that this kind of dry-stone masonry assemblages exhibits nonlinear behavior even under low pressures due to the absence of leveling mortar and imperfections at the joints with localized contact points. Finally, the imposed vertical displacement rate is investigated since the applied numerical formulation employs artificial damping to converge quasistatic solutions (Figure 9d). Different velocities prescribed for the loading plate and almost identical curves are obtained when the displacement rate is equal or smaller than $1 \times 10^{-2} \mathrm{~m} / \mathrm{s}$, whereas higher rates (e.g., $5 \times 10^{-2} \mathrm{~m} / \mathrm{s}$ ) cause unnecessary oscillations and stability problems during the analysis. It is worth noting that throughout this study, quasistatic analyses are performed using a displacement rate of $5 \times 10^{-2} \mathrm{~m} / \mathrm{s}$.

Therefore, with the validated DEM-based simulation of the dry-joint masonry arch, a comprehensive understanding is achieved. In the next section, the reference contact properties $\left(k_{n}=4 \mathrm{GPa} / \mathrm{m}, k_{s}=1.6 \mathrm{GPa} / \mathrm{m}\right.$ and $\phi_{0, \text { res }}=30.5$ degrees $)$ are used to analyze the impact response of the same stone masonry arch.

\subsection{Modeling Impact Loading Using DEM}

In this section, the discrete element model (used for quasistatics analysis) is modified to better capture the impact response of the same masonry arch subjected to impact loading. A drop-weight apparatus used in the benchmark study is modeled, where new rigid blocks are added to simulate the frame and the free-falling object, illustrated in Figure 11. The blocks representing frame are fixed and noncohesive bonds defined between the falling object and frame-blocks. The dimensions and specific weight of the free-falling object are adjusted to get the same mass employed in the experiment (as mentioned earlier in the article). Furthermore, the height of the object is arranged according to the benchmark study, which was varied during the testing. Similarly, abutments are fixed in the discrete element model. However, unlike the quasistatic analysis, dynamic calculations are performed in the real-time domain using stiffness proportional Rayleigh damping with a value of $1 \%$ critical at the fundamental frequency of $25 \mathrm{~Hz}$. Real inertia tensor and masses are utilized. The typical time step is determined around $3.5 \times 10^{-2} \mathrm{~s}$, satisfying the numerical stability of the explicit solution scheme employed in DEM. 


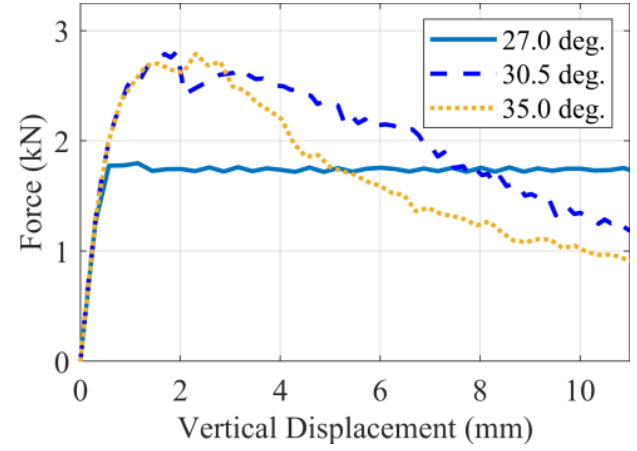

(a)

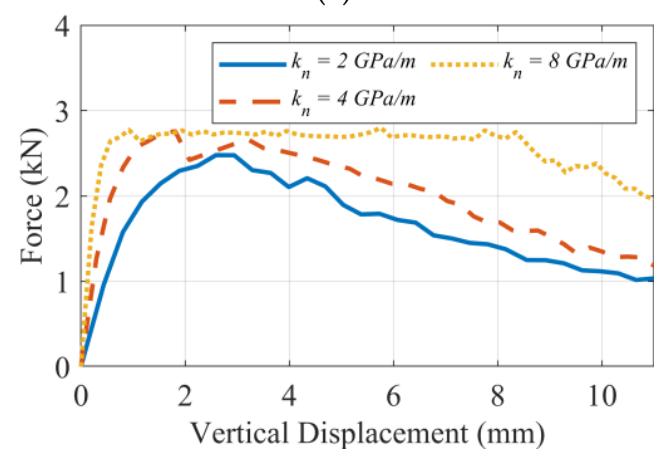

(c)

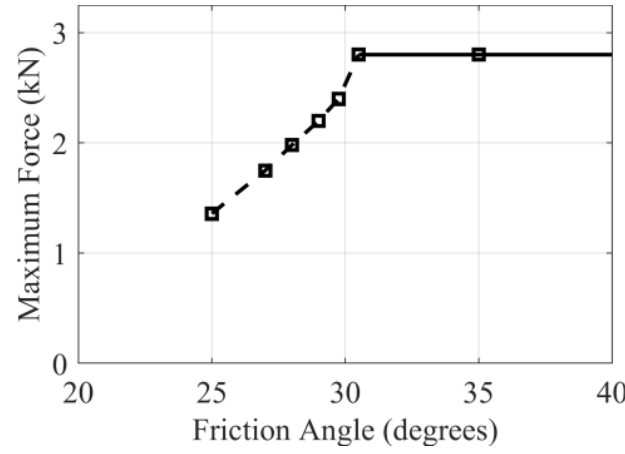

(b)

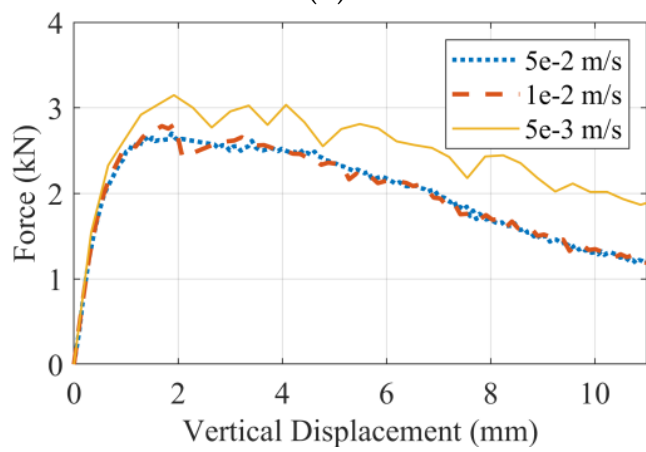

(d)

Figure 9. (a) Influence of the contact friction angle only the macroresponse of the arch and (b) loadcarrying capacity; sensitivity analysis on the (c) contact stiffness and (d) prescribed velocity on the loading plate.

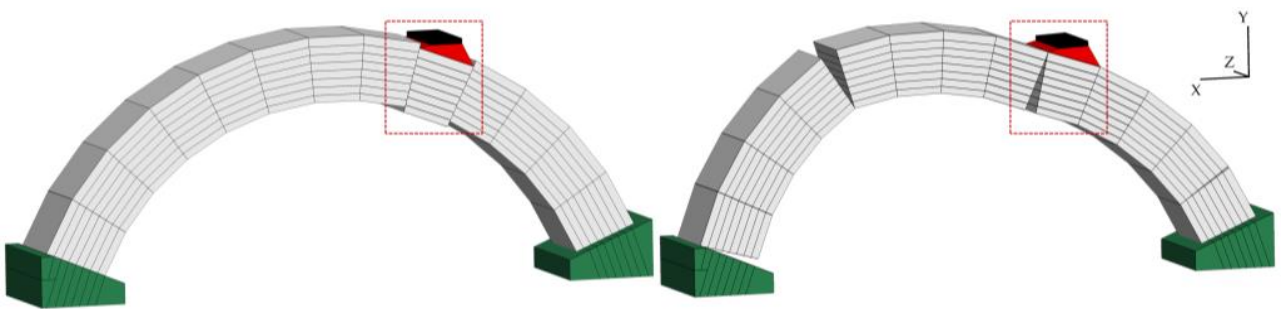

Figure 10. Pure sliding (left) and hinging (right) collapse mechanisms obtained using 27 and 35 degrees of friction angle at the joints, respectively.

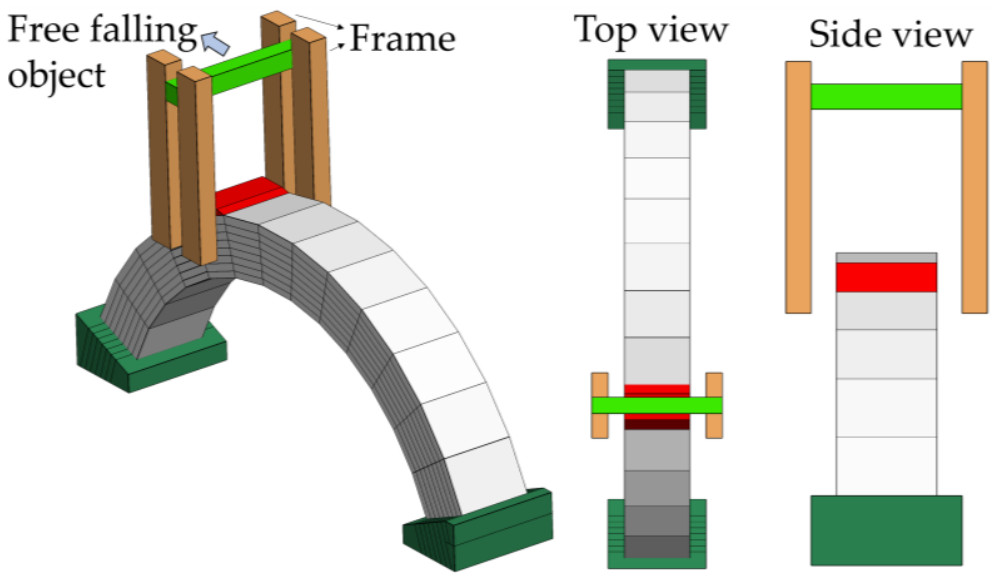

Figure 11. Impact test setup (used in the discrete element model).

The predicted damage mechanism for $\mathrm{M} 60 \mathrm{H} 30$ is shown in Figure 12a,b, which is in line with the experimental observations. No total collapse is observed in both experiment 
and computational model, but a permanent deformation is noted due to progressive sliding failure at the joint where the impact load acts, as shown in Figure 12a. Furthermore, three rotational hinges are observed once the block (subjected to direct impact load) slides, which is demonstrated in Figure 12b. However, the deformed configuration did not yield a collapse mechanism, and the dry-joint masonry arch found another state of equilibrium with a permanent deformation at the joints.

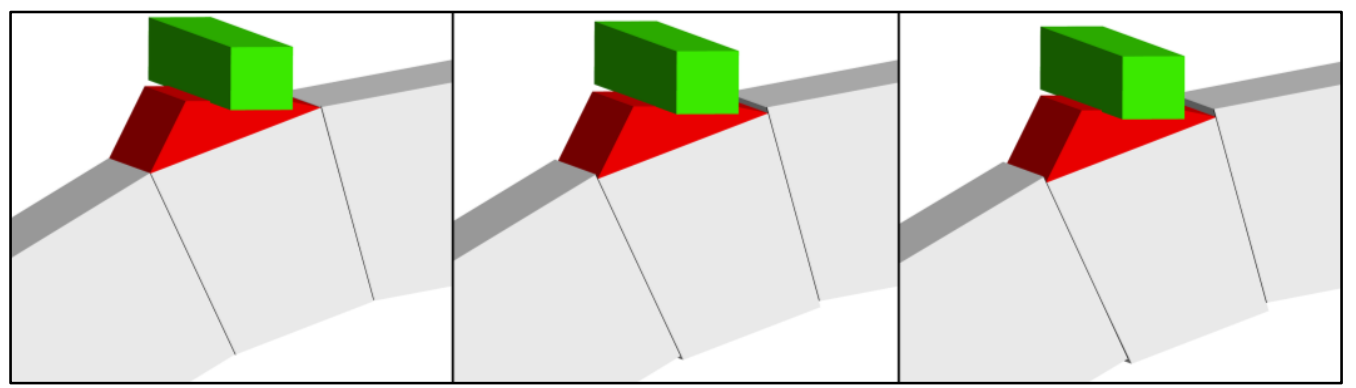

(a)

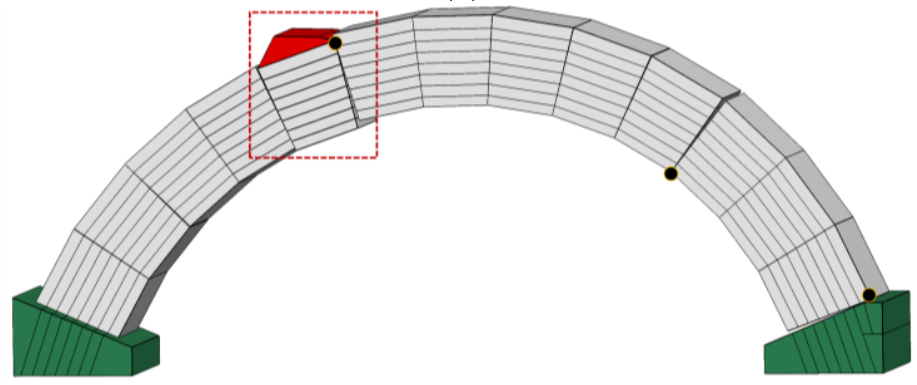

(b)

Figure 12. (a) Progressive sliding mechanism at the joints under impact loading (free-falling objectsnapshots are taken at $t=0, t=2.7 \mathrm{~ms}$ and $t=8.9 \mathrm{~ms}$-from left to right) and (b) overall response of the masonry arch $(\mathrm{M} 60 \mathrm{H} 30)$.

Additionally, the quantitative comparison between the predicted maximum deflections and experimental results are shown in Figure 13, where reasonable agreement can be observed for all three impact loadings with different heights of drop-weights (ranging from $20 \mathrm{~cm}$ to $30 \mathrm{~cm}$ ). These are the only tests where the stone masonry arch did not fail and only attained a maximum vertical deformation momentarily, accompanied by sliding failure. Moreover, it is interesting that in all three experiments with different dropping heights, the same structural behavior was noted during the experiment (as in the numerical predictions).

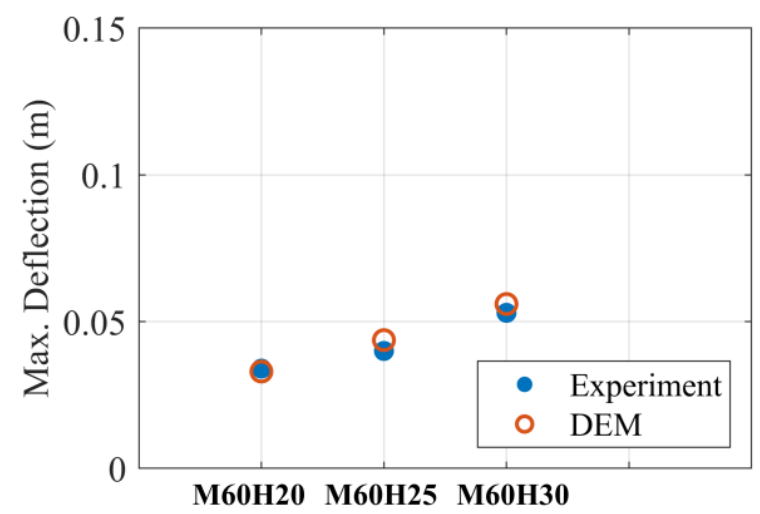

Figure 13. Comparison of maximum deflections obtained from the experiment and numerical analysis. 
As mentioned earlier, the reference properties used for the computational model is assigned in the dynamic model comprised of $k_{n}=4 \mathrm{GPa} / \mathrm{m}, k_{s}=1.6 \mathrm{GPa} / \mathrm{m}$, $\phi_{0, \text { res }}=30.5$ degrees and $1 \%$ stiffness proportional damping. A parametric analysis is done by considering different stiffness and damping ratios, ranging from 2 to $8 \mathrm{GPa} / \mathrm{m}$ and from 0.5 to $2.0 \%$, respectively (see Figure 14). The results show that the influence of each of these parameters becomes more pronounced when the initial height of the free-falling object (or block) gets higher. As can be seen from Figure 14 a, softer joints (i.e., $=2 \mathrm{GPa} / \mathrm{m}$ ) cause higher maximum deflection in the structure, whereas no stable solution is obtained when $0.5 \%$ stiffness proposal damping is used for M60H30 (Figure 14b). The analyses indicate that the applied modeling strategy indicates a sensitive response to contact stiffness and damping parameters. This outcome underlines the necessity for extra caution when determining these parameters in discrete element models.

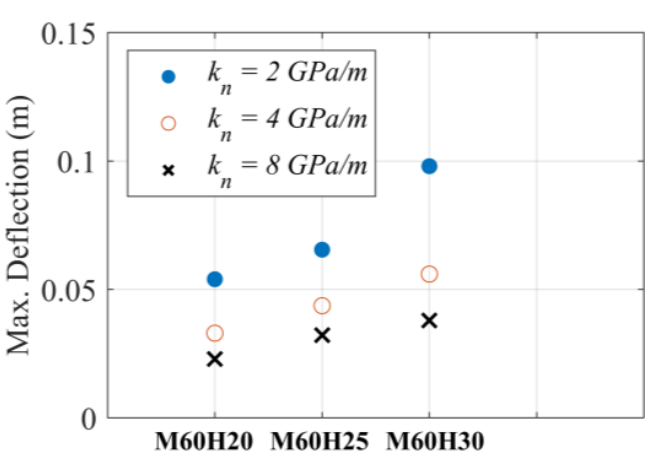

(a)

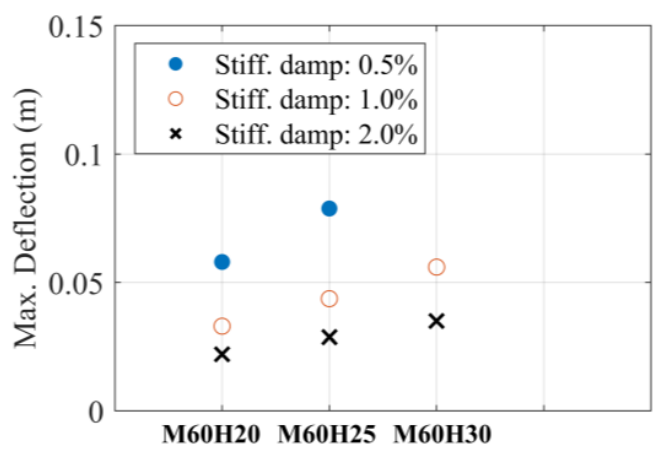

(b)

Figure 14. Effect of (a) stiffness and (b) damping ratio on the maximum deflections of stone masonry arch subjected to impact loading.

\section{Conclusions}

This research explores the structural behavior of a dry-joint stone masonry arch subjected to quasistatic and impact loading using a discontinuum-based analysis. A unique benchmark study is utilized to validate and further investigate the proposed computational models based on the discrete element method. In all numerical models, rigid blocks with noncohesive Coulomb slip contact constitutive law are employed, which fits the nature of the examined problem. First, nonlinear quasistatic analyses are performed, and experimental joint friction angle is predicted approximately by inverse engineering. The identical collapse mechanism is obtained via an applied modeling strategy where three rotational hinges and one sliding hinge are noted. Then, the same dry-joint stone masonry arch, tested under high-rate loading, is simulated. A similar loading condition, including a free-falling object (adopting different elevations), is generated using rigid blocks. The results demonstrate that DEM is able to capture large deformations accurately.

Moreover, contact stiffness has less influence on the capacity in the static analysis than the impact loading. It is revealed that discrete element models are very sensitive to the input parameters, especially for the impact type of loading. The stiffness and damping ratio are found influential on the displacement response of the arch, highlighting the need for more research. Therefore, the use of DEM to simulate dry-joint masonry arches subjected to low- and high-strain loading is exemplified, which has not been investigated in depth in the literature. This study can be extended to more complex masonry structures, including URM vaults and domes.

Author Contributions: Methodology, software, validation, writing, B.P.; writing-original draft preparation, review and editing, S.G.; Conceptualization, supervision, review and editing, P.B.L. All authors have read and agreed to the published version of the manuscript.

Funding: This research received no external funding. 
Institutional Review Board Statement: Not applicable.

Informed Consent Statement: Not applicable.

Data Availability Statement: Not applicable.

Conflicts of Interest: The authors declare no conflict of interest.

\section{References}

1. Gilbert, M.; Hobbs, B.; Molyneaux, T. The performance of unreinforced masonry walls subjected to low-velocity impacts: Experiments. Int. J. Impact Eng. 2002, 27, 231-251. [CrossRef]

2. Mayrhofer, C. Reinforced masonry walls under blast loading. Int. J. Mech. Sci. 2002, 44, 1067-1080. [CrossRef]

3. Kernicky, T.P.; Whelan, M.; Weggel, D.C.; Rice, C.D. Structural Identification and Damage Characterization of a Masonry Infill Wall in a Full-Scale Building Subjected to Internal Blast Load. J. Struct. Eng. 2015, 141, D4014013. [CrossRef]

4. Pourfalah, S.; Cotsovos, D.; Suryanto, B.; Moatamedi, M. Out-of-plane behaviour of masonry specimens strengthened with ECC under impact loading. Eng. Struct. 2018, 173, 1002-1018. [CrossRef]

5. Parisi, F.; Balestrieri, C.; Asprone, D. Blast resistance of tuff stone masonry walls. Eng. Struct. 2016, 113, 233-244. [CrossRef]

6. Tse, D.; Pereira, J.M.; Lourenço, P.B. Numerical Analysis of an Earthen Masonry Structure Subjected to Blast Loading. CivilEng 2021, 2, 969-985. [CrossRef]

7. Rafsanjani, S.H.; Lourenço, P.; Peixinho, N. Dynamic interface model for masonry walls subjected to high strain rate out-of-plane loads. Int. J. Impact Eng. 2015, 76, 28-37. [CrossRef]

8. Burnett, S.; Gilbert, M.; Molyneaux, T.; Beattie, G.; Hobbs, B. The performance of unreinforced masonry walls subjected to low-velocity impacts: Finite element analysis. Int. J. Impact Eng. 2007, 34, 1433-1450. [CrossRef]

9. Pulatsu, B.; Erdogmus, E.; Lourenço, P.B.; Lemos, J.; Tuncay, K. Simulation of the in-plane structural behavior of unreinforced masonry walls and buildings using DEM. Structures 2020, 27, 2274-2287. [CrossRef]

10. Pulatsu, B.; Bretas, E.M.; Lourenco, P. Discrete element modeling of masonry structures: Validation and application. Earthq. Struct. 2016, 11, 563-582. [CrossRef]

11. Milani, G.; Lourenço, P.B.; Tralli, A. Homogenized rigid-plastic model for masonry walls subjected to impact. Int. J. Solids Struct. 2009, 46, 4133-4149. [CrossRef]

12. Silva, L.C.; Lourenco, P.; Milani, G. Rigid block and spring homogenized model (HRBSM) for masonry subjected to impact and blast loading. Int. J. Impact Eng. 2017, 109, 14-28. [CrossRef]

13. Forgács, T.; Sarhosis, V.; Ádány, S. Shakedown and dynamic behaviour of masonry arch railway bridges. Eng. Struct. 2021, $228,111474$. [CrossRef]

14. Asad, M.; Dhanasekar, M.; Zahra, T.; Thambiratnam, D. Failure analysis of masonry walls subjected to low velocity impacts. Eng. Fail. Anal. 2020, 116, 104706. [CrossRef]

15. Asad, M.; Zahra, T.; Thambiratnam, D.P.; Chan, T.H.; Zhuge, Y. Assessing vibration induced damage in unreinforced masonry walls subject to vehicular impact-A numerical study. Eng. Struct. 2021, 245, 112843. [CrossRef]

16. Masi, F.; Stefanou, I.; Maffi-Berthier, V.; Vannucci, P. A Discrete Element Method based-approach for arched masonry structures under blast loads. Eng. Struct. 2020, 216, 110721. [CrossRef]

17. Saloustros, S.; Pelà, L.; Cervera, M.; Roca, P. An Enhanced Finite Element Macro-Model for the Realistic Simulation of Localized Cracks in Masonry Structures: A Large-Scale Application. Int. J. Arch. Herit. 2017, 12, 432-447. [CrossRef]

18. Lourenço, P.B. Computational Strategies for Masonry Structures; Delft University of Technology: Delft, The Netherlands, 1996.

19. Gönen, S.; Soyöz, S. Seismic analysis of a masonry arch bridge using multiple methodologies. Eng. Struct. 2020, 226, 111354. [CrossRef]

20. Zucchini, A.; Lourenço, P. A micro-mechanical homogenisation model for masonry: Application to shear walls. Int. J. Solids Struct. 2009, 46, 871-886. [CrossRef]

21. Cervera, M.; Pelà, L.; Clemente, R.; Roca, P. A crack-tracking technique for localized damage in quasi-brittle materials. Eng. Fract. Mech. 2010, 77, 2431-2450. [CrossRef]

22. Saloustros, S.; Cervera, M.; Pelà, L. Tracking multi-directional intersecting cracks in numerical modelling of masonry shear walls under cyclic loading. Meccanica 2017, 53, 1757-1776. [CrossRef]

23. De Felice, G. Out-of-Plane Seismic Capacity of Masonry Depending on Wall Section Morphology. Int. J. Arch. Herit. 2011, 5, 466-482. [CrossRef]

24. Gobbin, F.; de Felice, G.; Lemos, J.V. Numerical procedures for the analysis of collapse mechanisms of masonry structures using discrete element modelling. Eng. Struct. 2021, 246, 113047. [CrossRef]

25. Pulatsu, B.; Gencer, F.; Erdogmus, E. Study of the effect of construction techniques on the seismic capacity of ancient dry-joint masonry towers through DEM. Eur. J. Environ. Civ. Eng. 2020, 1-18. [CrossRef]

26. Erdogmus, E.; Pulatsu, B.; Gaggioli, A.; Hoff, M. Reverse Engineering a Fully Collapsed Ancient Roman Temple through Geoarchaeology and DEM. Int. J. Arch. Herit. 2020, 15, 1795-1815. [CrossRef]

27. Cundall, P.A. A computer model for simulating progressive, large-scale movements in blocky rock systems. In Proceedings of the International Symposium on Rock Mechanics, Nancy, France, 4-6 October 1971; Volume 2, pp. 47-65. 
28. Lemos, J.V. The Basis for Masonry Analysis with UDEC and 3DEC. In Computational Modeling of Masonry Structures Using the Discrete Element Method; IGI GLOBAL: Hershey, PA, USA, 2016; pp. 61-89. ISBN 9781522502319.

29. Lemos, J.V. Block modelling of rock masses. Concepts and application to dam foundations. Rev. Eur. Génie Civ. 2008, 12, 915-949. [CrossRef]

30. Gonen, S.; Pulatsu, B.; Erdogmus, E.; Karaesmen, E.; Karaesmen, E. Quasi-Static Nonlinear Seismic Assessment of a Fourth Century A.D. Roman Aqueduct in Istanbul, Turkey. Heritage 2021, 4, 401-421. [CrossRef]

31. Hart, R.; Cundall, P.; Lemos, J. Formulation of a three-dimensional distinct element model—Part II. Mechanical calculations for motion and interaction of a system composed of many polyhedral blocks. Int. J. Rock Mech. Min. Sci. Géoméch. Abstr. 1988, 25, 117-125. [CrossRef]

32. Lemos, J.V. Discrete Element Modeling of the Seismic Behavior of Masonry Construction. Buildings 2019, 9, 43. [CrossRef]

33. Cundall, P. Formulation of a three-dimensional distinct element model-Part I. A scheme to detect and represent contacts in a system composed of many polyhedral blocks. Int. J. Rock Mech. Min. Sci. Géoméch. Abstr. 1988, 25, 107-116. [CrossRef]

34. Itasca Consulting Group Inc. 3DEC Three Dimensional Distinct Element Code; Itasca Consulting Group Inc.: Minneapolis, MN, USA, 2013.

35. Birhane, T.H. Blast Analysis of Railway Masonry Bridges. Master's Thesis, University of Minho, Braga, Portugal, 2009.

36. Vasconcelos, G. Experimental Investigations on the Mechanics of Stone Masonry: Characterization of Granites and Behavior of Ancient Masonry Shear Walls. 2005. Available online: http:/ /hdl.handle.net/1822/17383 (accessed on 15 December 2021).

37. Godio, M.; Stefanou, I.; Sab, K. Effects of the dilatancy of joints and of the size of the building blocks on the mechanical behavior of masonry structures. Meccanica 2017, 53, 1629-1643. [CrossRef]

38. Pulatsu, B.; Gonen, S.; Erdogmus, E.; Lourenço, P.B.; Lemos, J.V.; Prakash, R. In-plane structural performance of dry-joint stone masonry Walls: A spatial and non-spatial stochastic discontinuum analysis. Eng. Struct. 2021, 242, 112620. [CrossRef]

39. Lourenco, P.; Oliveira, D.; Roca, P.; Orduña, A. Dry Joint Stone Masonry Walls Subjected to In-Plane Combined Loading. J. Struct. Eng. 2005, 131, 1665-1673. [CrossRef]

40. Lourenco, P.; Ramos, L. Characterization of Cyclic Behavior of Dry Masonry Joints. J. Struct. Eng. 2004, 130, 779-786. [CrossRef]

41. Lourenço, P.B. Analysis of historical constructions: From thrust-lines to advanced simulations. Hist. Constr. 2001, 91-116.

42. Pulatsu, B.; Kim, S.; Erdogmus, E.; Lourenço, P.B. Advanced analysis of masonry retaining walls using mixed discrete-continuum approach. Proc. Inst. Civ. Eng.-Geotech. Eng. 2021, 174, 302-314. [CrossRef] 